2015

\title{
Computer Forensic Projects for Accountants
}

Grover S. Kearns

University of South Florida, St. Petersburg

Follow this and additional works at: https://commons.erau.edu/jdfs|

Part of the Computer Engineering Commons, Computer Law Commons, Electrical and Computer Engineering Commons, Forensic Science and Technology Commons, and the Information Security Commons

\section{Recommended Citation}

Kearns, Grover S. (2015) "Computer Forensic Projects for Accountants," Journal of Digital Forensics, Security and Law: Vol. 10 : No. 3 , Article 1. DOI: https://doi.org/10.15394/jdfsl.2015.1203

Available at: https://commons.erau.edu/jdfsl/vol10/iss3/1

This Article is brought to you for free and open access by EMBRVFIDDLEF $\mid$ PURDUE the Journals at Scholarly Commons. It has been accepted for inclusion in Journal of Digital Forensics, Security and Law by an authorized administrator of Scholarly Commons. For more information, please contact commons@erau.edu.

(c)ADFSL 
@) (0) This work is licensed under a Creative Commons Attribution 4.0 International License

\title{
COMPUTER FORENSIC PROJECTS FOR ACCOUNTANTS
}

\author{
Grover S. Kearns \\ University of South Florida St. Petersburg \\ Program of Accountancy \\ St. Petersburg, FL 33701 \\ gkearns@mail.usf.edu
}

\begin{abstract}
Digital attacks on organizations are becoming more common and more sophisticated. Firms are interested in providing data security and having an effective means to respond to attacks. Accountants possess important investigative and analytical skills that serve to uncover fraud in forensic investigations. Some accounting students take courses in forensic accounting but few colleges offer a course in computer forensics for accountants. Educators wishing to develop such a course may find developing the curriculum daunting. A major element of such a course is the use of forensic software. This paper argues the importance of computer forensics to accounting students and offers a set of exercises to provide an introduction to obtaining and analyzing data with forensics software that are available free online. In most cases, figures of important steps are provided. Educators will benefit when developing the course learning goals and curriculum.
\end{abstract}

Keywords: Computer forensics; forensic accounting; accounting education

\section{INTRODUCTION}

Increased reliance on both technological and accounting skills has been recognized in research (Albrecht \& Sack, 2000; Cory \& Pruske, 2012). The increase of digital fraud has led many accountants to acquire advance information technology (IT) skills and certifications in order to qualify as IT auditors and forensic accountants (Davis, Schiller \& Wheeler, 2007). As routine accounting tasks are becoming highly automated an accountant's value is more likely to be determined by higher order skills such as those needed in forensic analysis (Hunton, 2002).
A data breach can result in extensive losses in both profits and reputation. The Target data breach that affected as many as 110 million customers received substantial adverse publicity and the total dollar loss is expected to be high (Tsu, 2014). In 2014, hacks were perpetrated on a large number of companies including Neiman Marcus, AT\&T, J.P. Morgan and Home Depot (Walters, 2014). In most cases, the attacks compromised confidential and financial information.

Companies may be legally obligated to provide confidentiality. Failure to protect personally identifiable information (PII) may subject the organization to fines and other 
(c) () This work is licensed under a Creative Commons Attribution 4.0 International License

penalties. The Gramm-Leach-Bliley Act (GLB) and Health Insurance Portability and Accounting Act (HIPPA) of 1996 stipulate that financial and health organizations are accountable for the safe guarding of PII (Pearson, 2008) and firms that operate abroad may be subject to the European Union Data Protection Directive which places stringent rules on the protection of private information.

Professional and regulatory bodies recognize the value of IT to accountants. The American Institute of Certified Public Accountants (AICPA) recognizes the importance of technology to the organization and to accountants. In its 2013 List of Top 10 Technology Initiatives the AICPA listed Securing the IT Environment, Ensuring Privacy and Preventing and Responding to Computer Fraud as top priorities (AICPA, 2013). The Public Company Accounting Oversight Board (PCAOB) has recommended that auditors receive IT training (O'Donnell and Moore, 2005). An analysis of 595 job listings for IT auditors found that a large percentage specifically mentioned technical skills/abilities including networking, security, database, experience with IT controls, and computer-assisted audit tools and techniques (Merhout \& Buchman, 2007). The Sarbanes-Oxley Act of 2002 and Statement on Auditing Standards No. 99 (SAS 99, 2002), "Consideration of Fraud in a Financial Statement Audit," extended expectations for auditors stating that,

"Electronic evidence often requires extraction of the desired data by an auditor with IT knowledge and skills or the use of an IT specialist ... it may be necessary for the auditor to employ computerassisted audit techniques ... to identify the journal entries and other

adjustments to be tested."

Source: AICPA (2012), p. 6.

The increased sophistication and complexities of information systems have created vulnerabilities that can be exploited to damage organizations by compromising confidential personal information, allowing unauthorized access to sensitive projects and intellectual property, and by concealing financial statement frauds and misappropriation of assets. In order to assess the nature and extent of these threats, to acquire and analyze evidence and to maintain a proper chain of custody, forensic accountants must possess a basic understanding of computer forensic techniques. This paper presents a set of exercises and projects that will be useful to educators creating an introductory course in computer forensics for accountants. This provides an important element in curriculum development and allows students to learn these skills in a hands-on environment. The exercises and projects use widely recognized software that is freely available.

\section{COMPUTER FORENSICS FOR ACCOUNTANTS}

Nelson, Philips \& Steuart (2010) define computer forensics as "The process of applying scientific methods to collect and analyze data and information that can be used as evidence." Thus, computer forensics addresses the methods and procedures necessary to investigate possible criminal and non-criminal conduct involving digital data. From an organizational perspective, investigations should initially proceed with the assumption that the case may be of a criminal nature so that all steps meet the statutory rules for admission of evidence. An 
(c) (1) This work is licensed under a Creative Commons Attribution 4.0 International License

understanding of computer forensics allows the accountant to make knowledgeable decisions regarding what steps to take and how to proceed during an investigation and not taint the evidence.

Computer forensics is considered by some to be dominated by IT and law-enforcement. Although both play important roles, accountants can also be a vital forensic resource. Accountants, in particularly auditors, are highly familiar with corporate information systems (IS), policies and internal controls, and often possess advanced analytical skills. They possess a broad understanding of the overall systems and databases, access rights, organizational roles and responsibilities which are critical to an effective forensic investigation. They are in a positon to recognize the normal routines of organizational agents and to recognize suspicious and unusual activities. IT specialists are primarily concerned with establishing defenses against external attacks and in maintaining and securing the internal environment through authorizations and access rights. Regardless of technical knowledge, organizational agents who inspect digital evidence must be forensically trained or they could taint evidence by opening and inspecting suspect files without first creating a mirror image and following chain-ofevidence procedures. Law-enforcement agents may have priorities that do not parallel and could even conflict with organizational goals. While the organization is most interested in identifying attacks and protecting digital assets, law-enforcement agents are primarily interested in apprehending the perpetrator. They may even seize the organization's computer as evidence. For these reasons, accountants, when properly trained, can provide another forensic asset through a combination of accounting and computer forensics skills that provide a special capability to investigate, analyze and report on suspicious patterns and anomalies and to follow the trail of unauthorized activities (Kearns, 2010).

Larger firms will usually have one or more internal auditors with forensic skills who are responsible for fraud detection and investigation (Pearson \& Singleton, 2008). Evidence in most organizational fraud cases is in digital form. With the need for increased vigilance it is imperative that these professionals be able to obtain, manage, and analyze digital forensic data in an effective manner. These accountants need, at minimum, training in the basics of computer forensics.

\section{COMPUTER FORENSIC TRAINING}

IT is now considered a basic skill for accountants (Hurt, 2007) and most undergraduate accounting students acquire an intermediate level IT competency. Schools accredited by the Association to Advance Collegiate Schools of Business (AACSB) usually include three courses in computer related knowledge and skills. First is an introductory computer class that covers productivity software including word processing, spreadsheets, database, email and slide presentation software. Second is a management information systems (MIS) class that covers the foundations of information resources, system management and security techniques, database concepts and IS management principles. Third is a course in accounting information systems (AIS) that focuses on internal controls for IS, transaction systems, systems design and documentation, system security, computer fraud, and IT governance. The AIS class may also cover advanced spreadsheet and database knowledge and generalized audit 
(c) () This work is licensed under a Creative Commons Attribution 4.0 International License

software such as Audit Control Language (Coglitore \& Matson, 2007).

Some accounting programs now offer courses in forensic accounting and a few colleges have full programs in forensic accounting. Graduate programs may offer an emphasis or track in forensic accounting in the Masters of Business Administration or Masters of Accountancy programs. The composition of the courses varies depending upon the number of courses offered. Schools that offer a full program or major will have a broader offering than those that only offer an emphasis or track in forensic accounting. Acquiring these skills can increase market appeal particularly for accounting students who wish to work as internal auditors or as IT or fraud auditors or as agents for the FBI, IRS or ATF who are important employers of accounting students. As a result of the increasing need for digital security and the importance of uncovering corporate fraud many universities are also creating courses in computer forensics (Busing, Null \& Forcht, 2005/2006).

Forensic accounting represents an integration of accounting, auditing and investigative skills that support the acquisition, maintenance, and analysis of relevant information in a manner that would be acceptable for judicial review and meet the requirements of professional oversight. It also extends to the formulation and presentation of findings in formal reports and court testimony as an expert witness. Forensic accountants command a set of skills that transcends the traditional expectations of accountants. These skills are acquired and enhanced through audit experience and increased investigative training. This allows the forensic accountant to analyze and interpret more complex business and nonbusiness issues in a manner that meets the highest requirements of reliability and integrity. As such, forensic accountants may be employed in a public or private capacity and play important roles in internal auditing departments of banks and insurance companies, governmental and law enforcement agencies, and as self-employed contractors for individuals and attorneys. Thus, the market for forensic accountants and the required skill sets are very well defined.

\section{COMPUTER FORENSICS COURSE EXERCISES AND PROJECTS}

Forensic accountants are often deficient in their understanding of computer forensics for several reasons. Many schools do not offer such a course because they lack qualified instructors. Also, the topics are not covered on the CPA exam and a large percentage of accounting students plan to acquire a CPA or similar certification such as Certified Management Accountant (CMA) or Certified Internal Auditor (CIA), none of which require the technical skills of computer forensics. Finally, accounting students who plan to take the CPA exam may have to meet the 150 hour rule adopted by many states and may perceive forensic skills as ones they can acquire in the future (Seda, Kramer \& Peterson, 2008). Thus, they may not be highly motivated to take a course that does not lead to a professional certification.

This deficiency, however, directly impacts the ability and effectiveness of the forensic accountant and makes him or her more reliant upon IT specialists for all steps requiring computer forensic analysis. Also, students may recognize that computer forensic skills are in-demand and may lead to careers in forensic accounting and IT auditing. Educators who recognize the 


\section{(a) (1) This work is licensed under a Creative Commons Attribution 4.0 International License.}

importance of computer forensic skills will be interested in exercises and projects that provide the accounting student with basic computer forensic techniques. The exercises and projects that follow introduce several widely recognized software products that are important to forensic analysis. Among other things, these exercises and projects illustrate how fraudsters can hide important information in files, how to inspect files for hidden data, how to acquire images from a suspect drive, how to recover deleted files and how to calculate hash values to insure the integrity of files. A set of student files for the exercises and projects are available upon request from the author. The exercises were performed in-class while the projects were performed by the individual student outside of class.

\subsection{Exercise and Project Requirements}

The projects use several applications available in demo versions.

1. WinHex Hexadecimal Editor

http://www.x-ways.net/

2. AccessData Forensic Tool Kit

http://accessdata.com/product-download/digital-forensics/forensic-toolkit-ftk-version-5.5

3. ProDiscover

http://www.arcgroupny.com/products/

4. HashCalc

http://www.slavasoft.com/hashcalc/

5. Eraser

http://eraser.heidi.ie/

6. OpenPuff Steganography

http://embeddedsw.net/OpenPuff Steganography Home.html

The following files are used in the exercises and projects and can be downloaded in zipped format. They should be placed in a work-folder named Projects. These files are available from the author although instructors may choose to create their own project files. 
(c) (9) This work is licensed under a Creative Commons Attribution 4.0 International License.

淠 AccountNo1.docx

AccountNo2.txt

D. Bruce Springsteen.mp3

2] Consent_to_Record_form.pdf

贯 $C O S O$ _COBIT.pptx

HxDShotLarge.png
HxDShotLarge.png

胃] ID Theft.docx

빨] james message.docx Music Notes.bmp

Pen Mike.jpg

wetel.docx
⿶ㅏㄹ] quote2.docx

때르. Shakespeare.docx

Wit] Social Engineering.doc

Sound Enhancer.gif

Spy Camera Finder.jpg

Wildlife.wmv

\subsection{Computer Forensic Exercises}

These exercises are intended to introduce the accounting student to knowledge and skills basic to computer forensics.

\section{Exercise 1: Numbering Systems}

Tantamount to the use of forensic software is the knowledge of the binary and hexadecimal numbering systems. All modern numbering systems have two things in common: (1) digits, and (2) placeholders. Each placeholder represents the base raised to a higher power. In the following tables, the second row is the placeholder and the third row is the power to which each value is raised.

\section{Placeholder and Power (Rows 1 and 2 respectively)}

(Note that the power is always one less than the placeholder.)

\begin{tabular}{|c|r|r|r|r|r|r|r|r|r|}
\hline 10 & 9 & 8 & 7 & 6 & 5 & 4 & 3 & 2 & 1 \\
\hline 9 & 8 & 7 & 6 & 5 & 4 & 3 & 2 & 1 & 0 \\
\hline
\end{tabular}

DECIMAL (Base 10 - Ten digits 0-9)

\begin{tabular}{|r|c|c|c|c|c|c|c|c|c|}
\hline \multicolumn{10}{|c|}{ Placeholder and Power } \\
\hline 10 & 9 & 8 & 7 & 6 & 5 & 4 & 3 & 2 & 1 \\
\hline $10^{9}$ & $10^{8}$ & $10^{7}$ & $10^{6}$ & $10^{5}$ & $10^{4}$ & $10^{3}$ & $10^{2}$ & $10^{1}$ & $10^{0}$ \\
\hline
\end{tabular}

Thus, in base 10 , the value 8,673 equals:

$8 \times 10^{3}+6 \times 10^{2}+7 \times 10^{1}+3 \times 10^{0}=8,000+600+70+3$

BINARY (Base 2 - Two digits 0 and 1 )

\begin{tabular}{|r|r|r|r|r|r|r|r|r|r|}
\hline \multicolumn{10}{|c|}{ Placeholder and Power } \\
\hline 10 & 9 & 8 & 7 & 6 & 5 & 4 & 3 & 2 & 1 \\
\hline $2^{9}$ & $2^{8}$ & $2^{7}$ & $2^{6}$ & $2^{5}$ & $2^{4}$ & $2^{3}$ & $2^{2}$ & $2^{1}$ & $2^{0}$ \\
\hline
\end{tabular}


(c) () This work is licensed under a Creative Commons Attribution 4.0 International License

Thus, in base 2, the value 11001100 equals:

$1 \times 2^{7}+1 \times 2^{6}+1 \times 2^{3}+1 \times 2^{2}=128+64+8+4=204$ base 10

HEXADECIMAL (Base 16 - Sixteen digits 0-F where $\mathrm{A}=10, \mathrm{~B}=11, \mathrm{C}=12, \mathrm{D}=13, \mathrm{E}=14$, $\mathrm{F}=15)$

\begin{tabular}{|r|r|r|r|r|r|r|r|r|r|}
\hline \multicolumn{10}{|c|}{ Placeholder and Power } \\
\hline 10 & 9 & 8 & 7 & 6 & 5 & 4 & 3 & 2 & 1 \\
\hline $16^{9}$ & $16^{8}$ & $16^{7}$ & $16^{6}$ & $16^{5}$ & $16^{4}$ & $16^{3}$ & $16^{2}$ & $16^{1}$ & $16^{0}$ \\
\hline
\end{tabular}

Thus, in base 16 , the value $1 \mathrm{~A} 5 \mathrm{~F}$ equals:

$1 \times 16^{3}+10 \times 16^{2}+5 \times 16^{1}+15 \times 16^{0}=4096+2560+80+15=6,751_{\text {base } 10}$

\begin{tabular}{|c|c|}
\hline $\begin{array}{l}\text { Student Exercise: Binary and Hexadecimal to } \\
\text { Decimal }\end{array}$ & Answers (in decimal values) \\
\hline \multicolumn{2}{|l|}{ Convert each of the following to decimal values. } \\
\hline 1. Binary: 1111 & 15 \\
\hline 2. Binary: & 255 \\
\hline 100000000 & 256 \\
\hline 4. Binary: & 170 \\
\hline 5. Hex: & 368 \\
\hline 6. Hex: & 2748 \\
\hline 7. Hex: & 255 \\
\hline 8. Hex: & 256 \\
\hline
\end{tabular}

\begin{tabular}{|c|c|c|}
\hline $\begin{array}{c}\text { Student Exercise: Decimal to } \\
\text { Binary and Hexadecimal }\end{array}$ & $\begin{array}{l}\text { Binary } \\
\text { Value }\end{array}$ & $\begin{array}{l}\text { Hexadecimal } \\
\text { Value }\end{array}$ \\
\hline $\begin{array}{l}\text { Convert each of the following to binary and } \\
\text { hex. } \\
\text { 1. } 88 \\
\text { 2. } 337 \\
\text { 3. } 1,024 \\
\text { 4. } 2,000\end{array}$ & $\begin{array}{lrrr}\text { 1. } & 0101 & 1000 \\
\text { 2. } & 0001 & 0101 & 0001 \\
\text { 3. } & 0100 & 0000 & 0000 \\
\text { 4. } & 0111 & 1101 & 0000\end{array}$ & $\begin{array}{ll}\text { 1. } & 58 \\
\text { 2. } & 151 \\
\text { 3. } & 400 \\
\text { 4. } & \text { 7D0 }\end{array}$ \\
\hline
\end{tabular}

(Note to instructor: Following the exercise refer students to a site that has a binary hex converter such as the one available at http://www.binaryhexconverter.com//) 
(c) (1) This work is licensed under a Creative Commons Attribution 4.0 International License

Exercise 2: Creating Hash Values (Checksums)

A hash, also known as a checksum or message digest, is a value that has no real meaning. Hashes are often used as control values such as the sum of employee id numbers for payroll applications. In accounting and forensics, hash values are created by computer algorithms that create a unique key string for any size of file. In most of our projects we would hash the file before and after testing to insure that the file itself has not been modified in any way.

The file size has no impact on the string length which is determined by the algorithm. In forensics the algorithms, MD5 and SHA256 have been popular. Calculators are readily available. We use HashCalc as shown in Figure 1.

1. Open HashCalc ${ }^{(}$and note the number of hash types. Open the MS Word file ID Theft.

2. Select the MD5, SHA256 and Tiger hash algorithms. Click Enter.

3. Take a screenshot of the results and add to your Results file and save to your Project_Work folder. See Figure1.

4. Close the ID Theft file.

5. Open the ID Theft file and again select the MD5, SHA256 and Tiger hash algorithms. Click Enter.

6. Compare the results to those from your previous screenshot. They should be the same.

7. At the bottom of the file type OK. Save the file.
8. Open the ID Theft file and again select the MD5, SHA256 and Tiger hash algorithms. Click Enter.

9. Compare the results to those from your previous screenshot. They should be the different.

Note that there are a number of different hashing algorithms and different hash values (aka message digests). MD5 and SHA256 are popularly used algorithms and have been accepted in courts of law.

\section{Exercise 3: Using Command Prompt}

\section{IP and MAC Addresses for Windows OS}

IP (Internet protocol) addresses are not unique to computers. They identify the node. If you switch computers the IP address remains with the node. However, each computer has a unique identifying number called the MAC (media access control) address. In this exercise you will use the Command Prompt to find your IP and MAC addresses.

On your home computer, go to Accessories / Command Prompt

If the cursor is not on the C: directory, enter the following...

$\mathrm{CD} \backslash$

Then enter ... ipconfig /all

Partial results of the ipconfig /all command appear below. Note the physical address (MAC address) and the IPv4 address. Write down your MAC and IPv4 addresses. 
(a) (1) This work is licensed under a Creative Commons Attribution 4.0 International License. Host Name . . . . . . : client1.microsoft.com

DNS Servers......: 10.1.0.200

Description . . . . . : 3Com 3C90x Ethernet Adapter

Physical Address. . . . . : $00-60-08-3 \mathrm{E}-46-07$

DHCP Enabled. . . . . . . Y Yes

Autoconfiguration Enabled.: Yes

IP Address. . . . . . . . . : 192.168.0.112

Subnet Mask . . . . . : 255.255.0.0

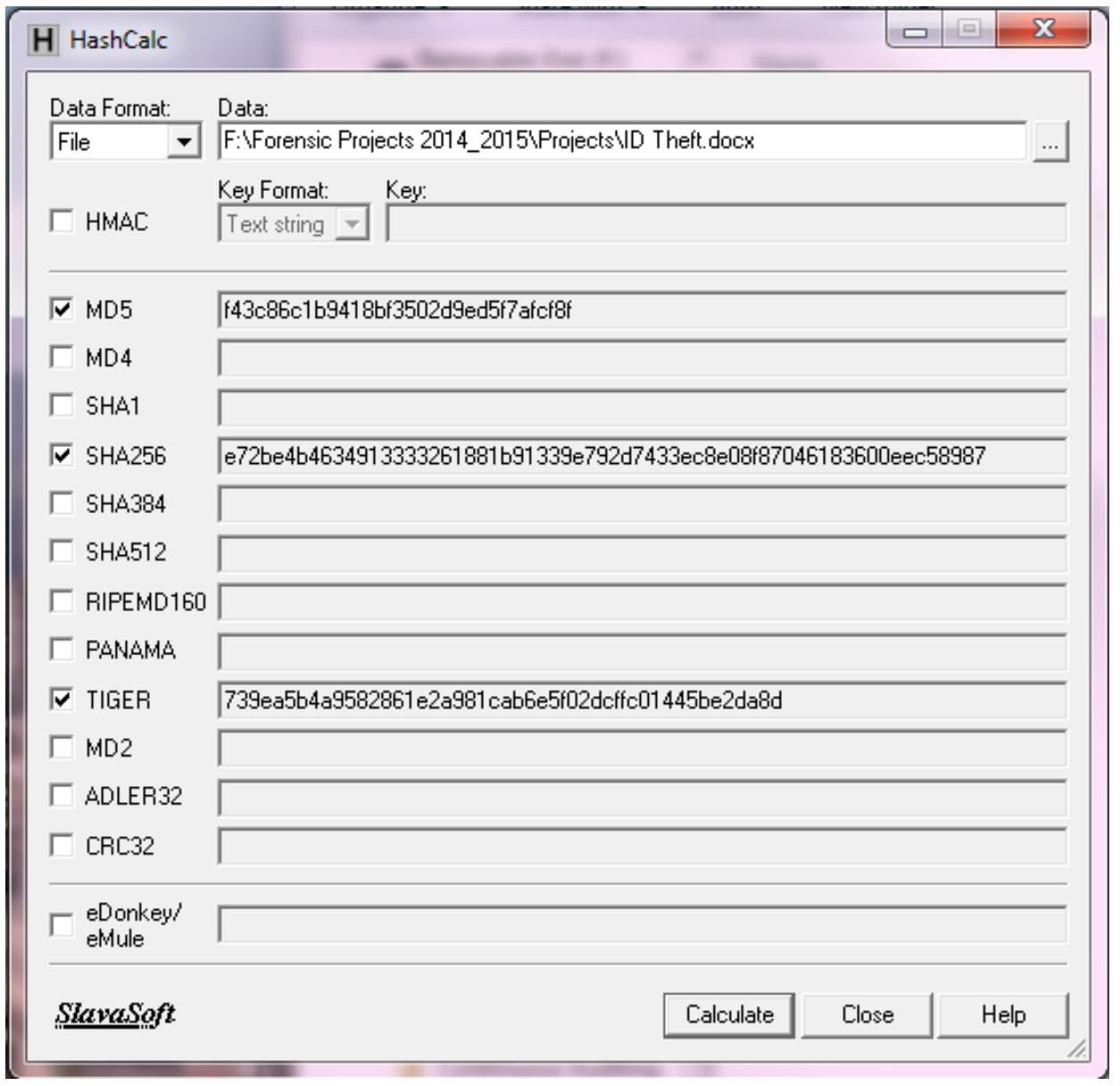

Figure 1. Original Hash Values for ID_Theft.doc

\section{Command Prompt and DOS Commands}

At the command prompt attempt the following commands. [ ] is for annotation only.

This assumes the file is on your C: drive. If not, then insert the full path to the file. 
(9) 8 This work is licensed under a Creative Commons Attribution 4.0 International License.

Enter the following commands (commands are shown in uppercase to separate them from the file names. Commands can usually be entered in upper or lower case).

C:

[this will take you to the c: drive]

TYPE C: \Shakespeare.txt

[this will type out the contents of the file]

RENAME C: \Shakespeare.txt WilliamShakespeare.txt [renames the file]

MD Projects

$\mathrm{DIR} * *$

RD Projects

DIR *.*

DIR C: $\backslash$ Projects $\backslash *$.doc [creates a new folder name Projects]

[lists all files in the current folder: note new folder]

[removes folder named Projects]

[lists all files in the current folder]

[lists all .doc files in the Projects folder]

PrintScreen the CommandPrompt window and enter the following command to clear the screen: CLS

\section{$\underline{\text { Print System Information }}$}

Click Start \Run

type msconfig

In the System Configuration table select Startup and examine what programs are opened when you start your computer. Do you want all of these to open? If not, then deselect the box for unwanted applications.

\section{Exercise 4: ASCII and HEX Codes}

ASCII (American Standard Code for Information Interchange) is used for storage of all text values in personal computers. In ASCII each letter, digit and special character is represented in eight bits or one byte and a total of 128 different characters can be represented. From the table in Figure 2, insert the code for each item in the table below in its hexadecimal equivalent. Leave a space between each byte. (An extended code, Unicode, is often used in place of ASCII because it allows for more than the 128 characters. However, the right-most 8 bits in Unicode are the same as for ASCII.)
In the System Configuration table select Tools \Security Center and click Launch. Click Internet Options and explore the trusted certifications.

PrintScreen the System Information for your computer.

\begin{tabular}{|l|l|}
\hline ITEM & $\begin{array}{l}\text { ASCII VALUE IN } \\
\text { HEX }\end{array}$ \\
\hline MI 5 & \\
\hline Microsoft Word & \\
\hline 123 Oak Ave. & \\
\hline$(555) 123-1234$ & \\
\hline$\$ 50.46$ & \\
\hline
\end{tabular}

\subsection{Computer Forensic Projects}

\section{Forensic Project 1: File Headers and Image Files}

Opening files in either NotePad or a hexadecimal (hex) editor provides initial information for examination of files. The investigator can also determine if the file 
(c) () This work is licensed under a Creative Commons Attribution 4.0 International License

type is correct. For each file, you will open it in both NotePad and WinHex. In WinHex you will note the first eight bytes in positions 0-7. Each byte will be two characters ranging from $00-\mathrm{FF}$. These eight bytes often are the signature for the filetype. However, for MS Windows, the signature is the same for Word, Excel and PowerPoint but different for Access. To determine the Microsoft Office filetype you can go to offset hex 512 (200) for doc, xls and ppt files. Figure 3 shows the different signatures for MS Office files. For a more extensive list of file signatures visit Professor Gary Kessler's site http://www.garykessler.net/library/file_sigs.h

$\underline{t m l}$.

Step 1: Create a work-folder on your personal computer c: drive named Projects.

Step 2: Download and extract the projects.zip from the instructor's web site.

Step 3: Open the following files in both Notepad and WinHex. Determine the file type for each and indicate how you could identify the file type in Notepad and the hex editor. Simply copy the identifying information into the table. If it does not appear to be identifiable then type NI. 
(a) $(0)$ This work is licensed under a Creative Commons Attribution 4.0 International License.

\begin{tabular}{|c|c|c|c|c|c|c|c|c|c|c|c|}
\hline \multicolumn{3}{|c|}{ ASCll Hex Symbol } & \multicolumn{3}{|c|}{ ASCII Hex Symbol } & \multicolumn{3}{|c|}{ ASCII Hex Symbol } & \multicolumn{3}{|c|}{ Ascll Hex Symbol } \\
\hline 0 & 0 & NUL & 16 & 10 & DLE & 32 & 20 & (space) & 48 & 30 & 0 \\
\hline 1 & 1 & $\mathrm{SOH}$ & 17 & 11 & DC1 & 33 & 21 & ! & 49 & 31 & 1 \\
\hline 2 & 2 & STX & 18 & 12 & $\mathrm{DC} 2$ & 34 & 22 & $"$ & 50 & 32 & 2 \\
\hline 3 & 3 & ETX & 19 & 13 & DC3 & 35 & 23 & \# & 51 & 33 & 3 \\
\hline 4 & 4 & EOT & 20 & 14 & DC4 & 36 & 24 & $\$$ & 52 & 34 & 4 \\
\hline 5 & 5 & ENQ & 21 & 15 & NAK & 37 & 25 & $\%$ & 53 & 35 & 5 \\
\hline 6 & 6 & ACK & 22 & 16 & SYN & 38 & 26 & $\&$ & 54 & 36 & 6 \\
\hline 7 & 7 & BEL & 23 & 17 & ETB & 39 & 27 & 1 & 55 & 37 & 7 \\
\hline 8 & 8 & BS & 24 & 18 & CAN & 40 & 28 & ( & 56 & 38 & 8 \\
\hline 9 & 9 & TAB & 25 & 19 & EM & 41 & 29 & ) & 57 & 39 & 9 \\
\hline 10 & A & LF & 26 & $1 \mathrm{~A}$ & SUB & 42 & $2 \mathrm{~A}$ & $\approx$ & 58 & $3 A$ & : \\
\hline 11 & $\mathrm{~B}$ & $\mathrm{VT}$ & 27 & 1B & ESC & 43 & $2 \mathrm{~B}$ & + & 59 & $3 B$ & ; \\
\hline 12 & $\mathrm{C}$ & FF & 28 & $1 \mathrm{C}$ & $\mathrm{FS}$ & 44 & $2 \mathrm{C}$ & , & 60 & $3 \mathrm{C}$ & $<$ \\
\hline 13 & D & $\mathrm{CR}$ & 29 & 1D & GS & 45 & $2 \mathrm{D}$ & - & 61 & $3 \mathrm{D}$ & $=$ \\
\hline 14 & $\mathrm{E}$ & SO & 30 & $1 \mathrm{E}$ & RS & 46 & $2 \mathrm{E}$ & & 62 & $3 E$ & $>$ \\
\hline 15 & $\mathrm{~F}$ & $\mathrm{SI}$ & 31 & $1 F$ & US & 47 & $2 \mathrm{~F}$ & I & 63 & $3 F$ & $?$ \\
\hline \multicolumn{3}{|c|}{ ASCII Hex Symbol } & \multicolumn{3}{|c|}{ ASCII Hex Symbol } & \multicolumn{3}{|c|}{ ASCII Hex Symbol } & \multicolumn{3}{|c|}{ ASCII Hex Symbol } \\
\hline 64 & 40 & @) & 80 & 50 & $\mathrm{P}$ & 96 & 60 & $\cdot$ & 112 & 70 & $\mathrm{p}$ \\
\hline 65 & 41 & A & 81 & 51 & $Q$ & 97 & 61 & a & 113 & 71 & $q$ \\
\hline 66 & 42 & B & 82 & 52 & $\mathrm{R}$ & 98 & 62 & b & 114 & 72 & $\mathrm{r}$ \\
\hline 67 & 43 & $\mathrm{C}$ & 83 & 53 & $S$ & 99 & 63 & C & 115 & 73 & s \\
\hline 68 & 44 & $\mathrm{D}$ & 84 & 54 & $\mathrm{~T}$ & 100 & 64 & d & 116 & 74 & $t$ \\
\hline 69 & 45 & $E$ & 85 & 55 & $\mathrm{U}$ & 101 & 65 & $\mathrm{e}$ & 117 & 75 & u \\
\hline 70 & 46 & $\mathrm{~F}$ & 86 & 56 & $\vee$ & 102 & 66 & $f$ & 118 & 76 & $\mathrm{v}$ \\
\hline 71 & 47 & G & 87 & 57 & W & 103 & 67 & $\mathrm{~g}$ & 119 & 77 & w \\
\hline 72 & 48 & $\mathrm{H}$ & 88 & 58 & $x$ & 104 & 68 & $\mathrm{~h}$ & 120 & 78 & $x$ \\
\hline 73 & 49 & I & 89 & 59 & $\mathrm{Y}$ & 105 & 69 & $\mathbf{i}$ & 121 & 79 & $y$ \\
\hline 74 & $4 \mathrm{~A}$ & $\mathrm{~J}$ & 90 & $5 \mathrm{~A}$ & Z & 106 & $6 \mathrm{~A}$ & j & 122 & $7 \mathrm{~A}$ & z \\
\hline 75 & $4 \mathrm{~B}$ & $\mathrm{~K}$ & 91 & $5 \mathrm{~B}$ & [ & 107 & $6 \mathrm{~B}$ & $\mathrm{k}$ & 123 & 7B & \{ \\
\hline 76 & $4 \mathrm{C}$ & $\mathrm{L}$ & 92 & $5 \mathrm{C}$ & i & 108 & $6 \mathrm{C}$ & I & 124 & $7 \mathrm{C}$ & 1 \\
\hline 77 & 4D & $\bar{M}$ & 93 & $5 \mathrm{D}$ & ] & 109 & $6 \mathrm{D}$ & $\mathrm{m}$ & 125 & 7D & \} \\
\hline 78 & $4 \mathrm{E}$ & $\mathrm{N}$ & 94 & $5 \mathrm{E}$ & $\wedge$ & 110 & $6 \mathrm{E}$ & $\mathrm{n}$ & 126 & 7E & $\sim$ \\
\hline 79 & $4 \mathrm{~F}$ & 0 & 95 & $5 \mathrm{~F}$ & _- & 111 & $6 \mathrm{~F}$ & 0 & 127 & $7 F$ & \\
\hline
\end{tabular}

Figure 2. ASCII Code Source http://ascii.cl/

Tables with extended binary information are available at http://www.ascii-code.com/

Instructions: Insert the identifying code and the hex signatures for each of the files.

\begin{tabular}{|l|c|c|c|}
\hline File & Filet & NotePad & Hex Editor \\
\hline Consent_to_Record_F & .pdf & & \\
\hline
\end{tabular}




\section{(c) $(1)$ This work is licensed under a Creative Commons Attribution 4.0 International License.}

\begin{tabular}{|l|l|l|l|}
\hline orm & & & \\
\hline HxDShotLarge & .png & & \\
\hline Sound Enhancer & .gif & & \\
\hline Social Engineering &. doc & & \\
\hline Pen Mike & .jpg & & \\
\hline AccountNo2 &. txt & & \\
\hline Bruce Springsteen &.$m p 3$ & & \\
\hline Wildlife &.$w m v$ & & \\
\hline
\end{tabular}

Step 4: Open the Social Engineering file in WinHex and change the first eight bytes to resemble a .jpg file. Save the file and then try to open it. What happens? Open it again in WinHex and change the first eight bytes back to their correct values. Save and reopen. It is now back to its original state. This process allows fraudsters to conceal files in plain sight.

\begin{tabular}{|c|rrrrrrrr|}
\hline Offset & 0 & 1 & 2 & 3 & 4 & 5 & 6 & 7 \\
\hline 00000000 & D0 & CF & 11 & E0 & A1 & B1 & 1 A & E1 \\
\hline
\end{tabular}

The above file signature is the same for MS Office doc, xls, and ppt

00000200 EC A5 C1 00 OF C0 0904

$00000210 \quad 00 \quad 00 \quad 00 \quad 10 \quad 00 \quad 00 \quad 00 \quad 00$

Signatures for doc, xls, and ppt can be found at offset hex 512 (200). The above is the .doc signature.

\begin{tabular}{c|rrrrrrrr} 
Offset & 0 & 1 & 2 & 3 & 4 & 5 & 6 & 7 \\
00000000 & 50 & $4 \mathrm{~B}$ & 03 & 04 & 14 & 00 & 06 & 00
\end{tabular}

MS Office docx, xlsx, and pptx all have the file signature shown above.

Figure 3. File Signatures for MS Word, Excel and PowerPoint

\section{Working with Image Files}

A basic tenant of forensic investigations is to never work on the original file. First create a mirror image (bit-by-bit copy) and work on the copy. The student will image the contents of a USB drive (the suspect drive) and perform a search on the image file.

Learning Goal(s): Wiping Disks, Creating a USB Image File; Searching an Image File 
(a) (1) This work is licensed under a Creative Commons Attribution 4.0 International License

Software: Eraser, ProDiscover Basic (this can also be performed with FTK Imager)

Files: Shakespeare, james message, ID Theft, quote1, quote2, AccountNo1, AccountNo2, COSO_COBIT, Social Engineering, Sound Enhancer, Pen Mike, Spy Camera Finder,

Instructions: First, you will delete the files on your USB drive and then add the files you wish to have in your image file. Be sure that you have saved your USB files to another drive.

1. Start Eraser and be sure that the correct drive is selected. In settings, choose those for Pseudorandom 1 Pass (see Figure 4). Run Eraser.

2. Copy the above files to your USB drive.

3. Start ProDiscover Basic and click Run Administrator. In the Launch Dialog box, click the New Project tab and enter the project number Proj01, and project name Proj01.

4. Click Action and click Capture Image. For Source Drive, select your USB drive. For Destination also select your USB drive. Name the destination file ForensicProject. Use your initials for Technician Name and 01 for image number. Click OK. This may take several minutes. An image file (ForensicProject.eve) will be created which will be a bit-by-bit copy of your USB.

5. Start ProDiscover Basic and click Run Administrator. In the Launch Dialog box, click the New Project tab and enter the project number: Proj01, and project name:
6. Click Action from the menu, point to Add and click Image File.

7. In your work folder, click the file ForensicProject.eve and then click Open. If the Auto Image Checksum message box opens, click No (we will not calculate a checksum on this project).

8. In the tree view, click to expand Content View, click to expand Images, and then click the pathname containing your image file. (Files are listed in the work area. See Figure 5).

9. Right-click any file and click View this will start the associated program such as MS Word or Excel. View the file and then exit the program. Try this with several types of files.

10. To search for the keyword "bank" click the Search toolbar button (the binoculars icon) to open the Search dialog box.

11. Click the Content Search tab. If necessary, click the ASCII button and the Search for the Pattern(s) option button. Type bank in the list box for search keywords. Under Select the Disk/Image(s) click the drive that you are searching and then click $\mathbf{O K}$.

12. In the tree view, click to expand Search Results and then click Content Search results to specify the search type and note the search results in Figure 6.

13. To search all clusters, click the Cluster Search tab and search for bank. This will take more time because all clusters are being searched. Note the results.

14. Save the project. Click File, Save Project from the menu. 
(c) () This work is licensed under a Creative Commons Attribution 4.0 International License.

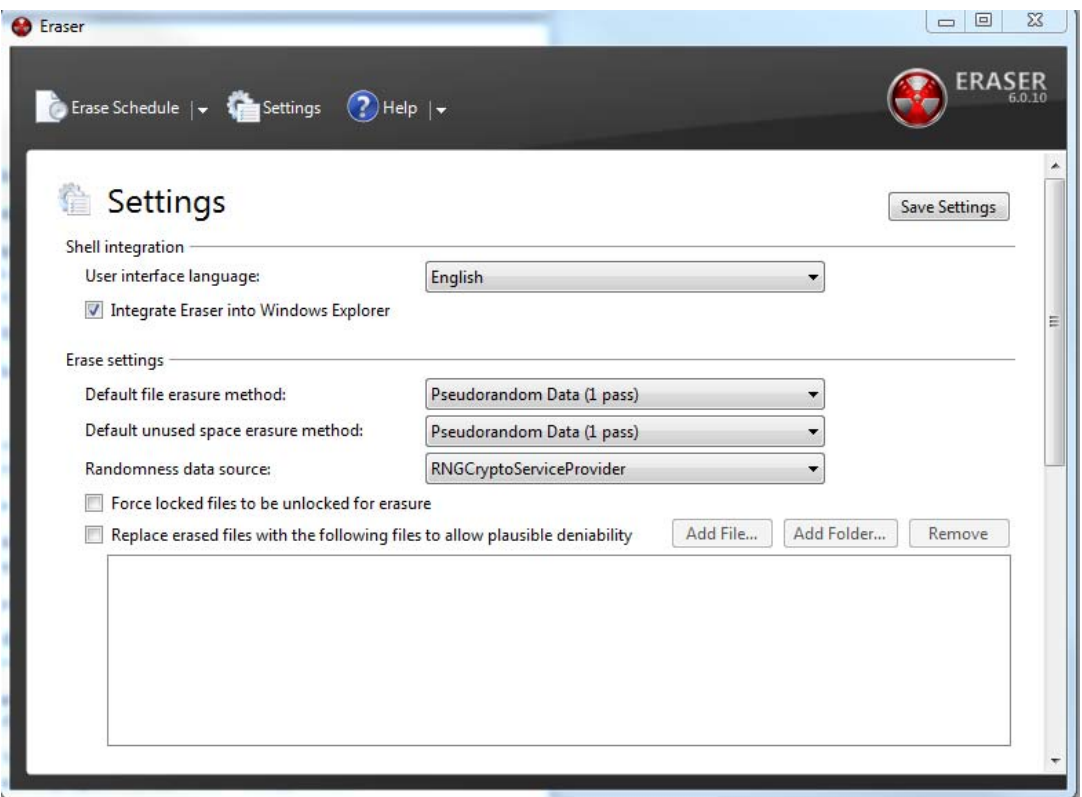

Figure 4. Eraser Settings 
(a) (0) This work is licensed under a Creative Commons Attribution 4.0 International License.

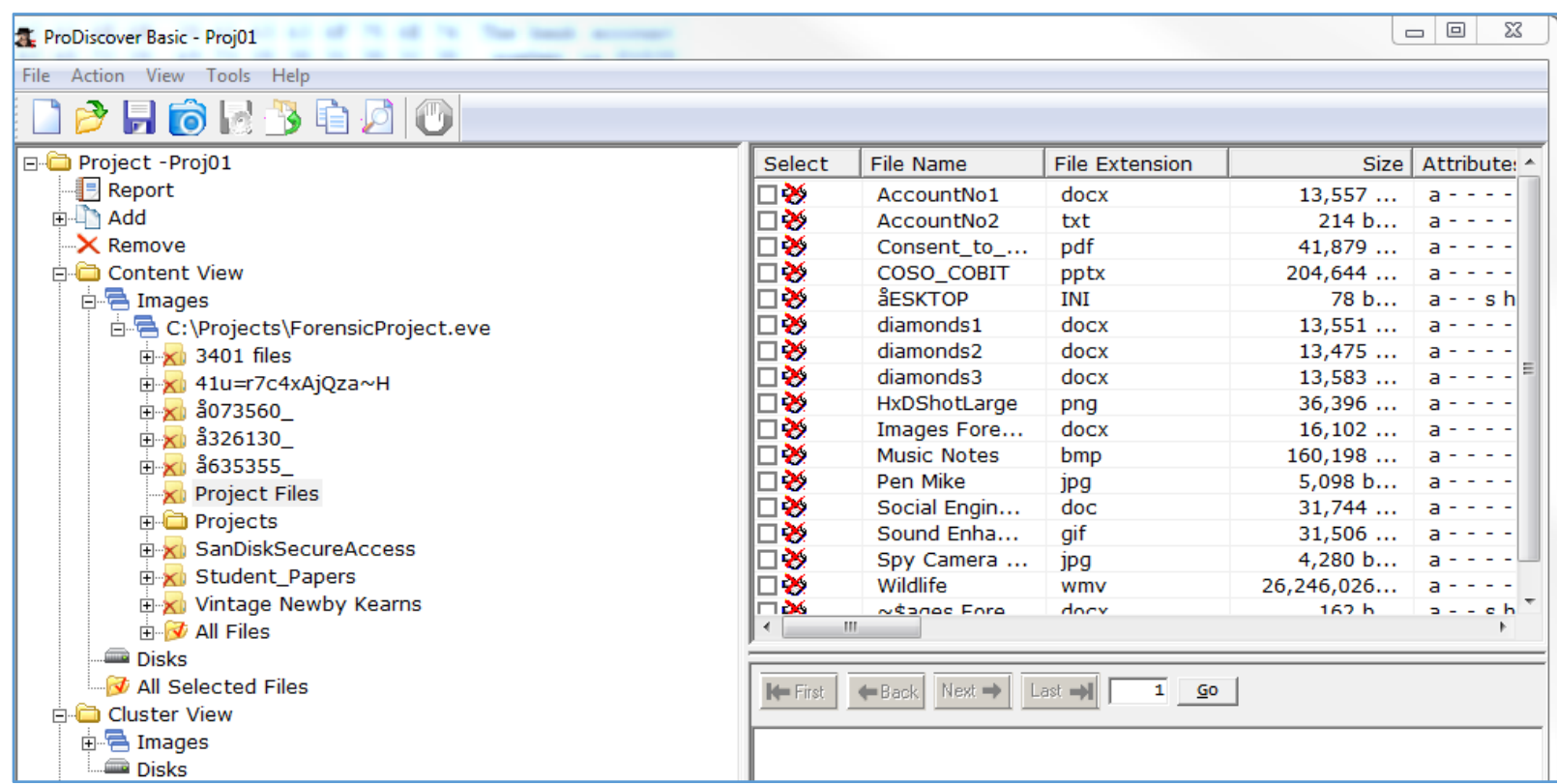

Figure 5. Expanded Path in Content View

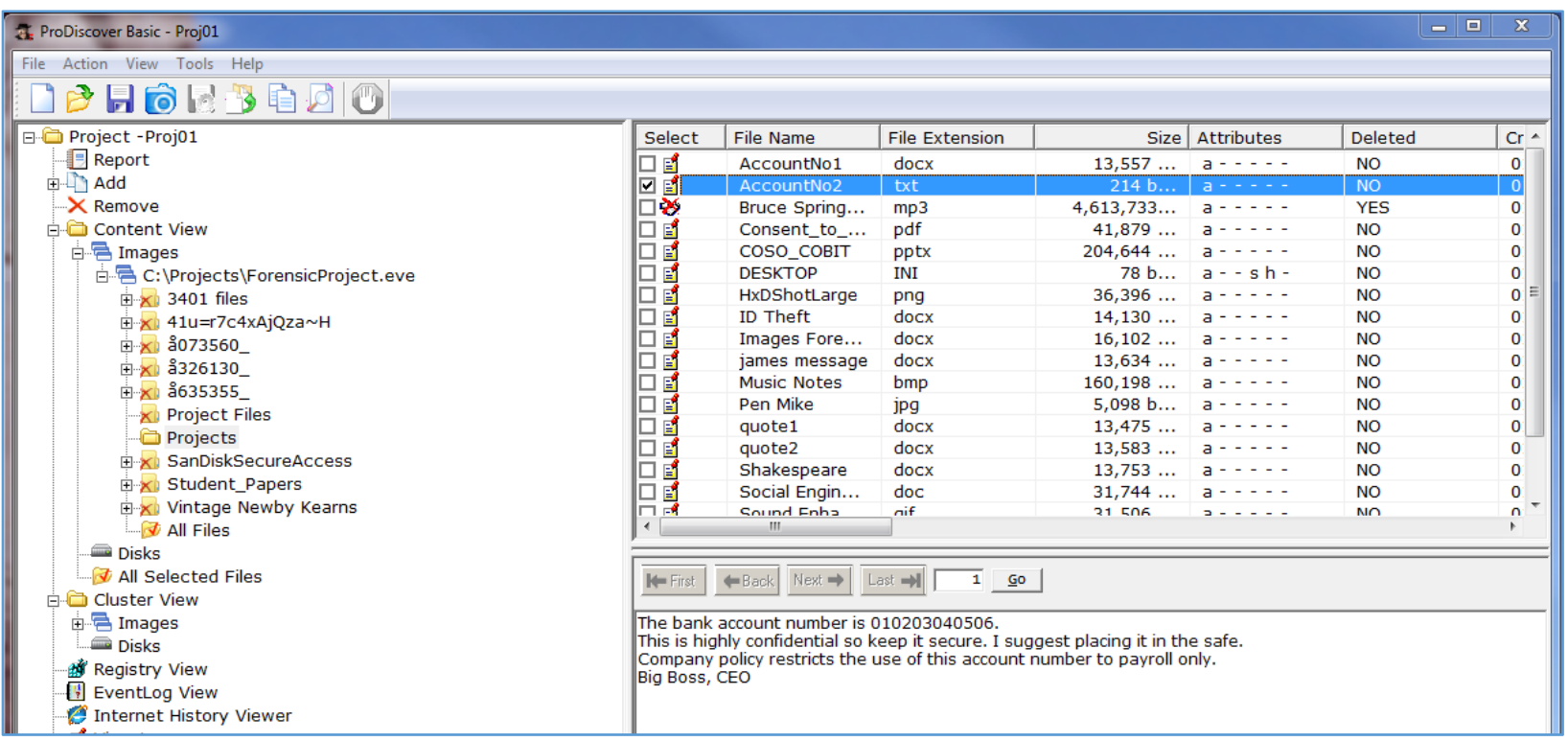

Figure 6. Search for the Term "Bank" 
(c) (1) This work is licensed under a Creative Commons Attribution 4.0 International License

Forensic Project 2: Searching Unix Image Files

Learning Goals: Search a Unix .dd image file for hidden account numbers

Software: ProDiscover Basic (this can also be performed with FTK Imager)

Files: RawFormat.dd

Raw format files are non-proprietary and are often used because they can be viewed in a number of tools.

1. Start ProDiscover Basic and click Run Administrator. In the Launch Dialog box, click the New Project tab and enter the project number Proj02, and project name Proj02. Click File, Save Project.

2. Click Action from the menu, point to Add and click Image File.

3. In your work folder, click the file RawFormat.dd and then click Open. If the Auto Image Checksum message box opens, click No (we will not calculate a checksum on this project). Note that this is a Unix .dd image file.

4. In the tree view, click to expand Content View, click to expand Images, and then click the pathname containing your image file. (Files are listed in the work area.)

5. Click View, Gallery View. Scroll through the graphics files on the drive image. To discover the account numbers you will have to inspect each of these files. In the Add Comment dialog box enter a brief comment and click OK. This will add your case notes to the ProDiscover reports.

6. For each file of interest, open the file click the Search toolbar button (the binoculars icon) to open the Search dialog box.

7. Click the Content Search tab. If necessary, click the ASCII button and the Search for the Pattern(s) option button. Type the account number 0102030405 in the list box for search keywords. Under Select the Disk/Image(s) click the drive that you are searching (see Figure7) and then click OK.

8. In the tree view, click to expand Search Results and then click Content Search results to specify the search type and note the search results.

9. To search all clusters, click the Cluster Search tab and repeat the search using the account number 0102030405 as the search keyword. Enter notes in the Add Comment dialog box when your search is successful.

10. Click Report in the tree view and review the report to insure it is complete. A complete and concise report is critical to the forensic investigation.

11. Click the Export toolbar button. In the dialog box click the RTF Format button (for rich text) and type Bank Account Report in the File Name text box, and then click OK. You have now saved the project report. 
(a) $\frac{8}{\sigma 2}$ This work is licensed under a Creative Commons Attribution 4.0 International License,

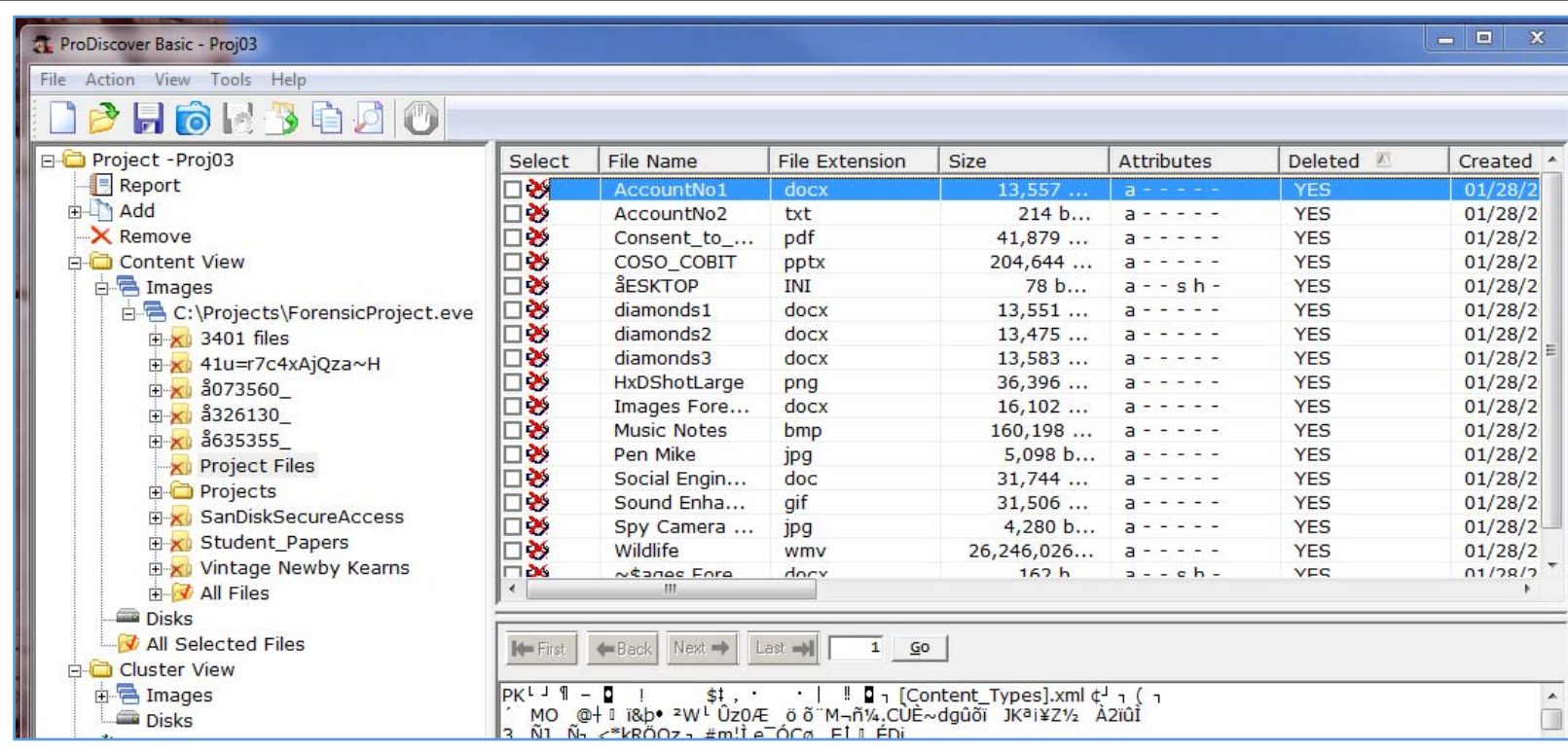

Figure \%. Image File Displayed in Work Area

\section{Forensic Project 3: Extract Allocated and Unallocated Files}

Learning Goals: Extract allocated files and unallocated files separately

Software: ProDiscover Basic

Files: ForensicProject.eve

1. Start ProDiscover Basic and click Run Administrator. In the Launch Dialog box, click the New Project tab and enter the project number Proj03 and project name Proj03 . Then click Open.

2. In the tree view, click to expand Add, click Image File. In your work folder, click the ForensicProject.eve file and then click Open and click No in the Auto Image Checksum message box. Save the project to your folder.

3. In the tree view, click to expand Content View, click to expand Images, and then click the pathname containing the image file. Examine the files displayed in the work area. Under the column heading Deleted note that the files are either YES (indicating deleted or unallocated files) or NO (indicating active or allocated files).

4. Sort on the Deleted column by clicking the Deleted header.

5. To extract the allocated files, rightclick each of the files designated as $\mathrm{NO}$ in the Deleted Column and click Copy File. In ProDiscover Basic this must be performed for each separate file.

6. To extract the unallocated files, right-click each of the files designated as YES in the Deleted Column and click Copy File. As you click a check-box, the Add Comment dialog box appears. Note the filename and type that has been deleted. (In practice, you would first examine each of these files and add a meaningful comment.)

\section{Forensic Project 4: Creating a USB Write-Blocker}

This project creates two desk-top icons that enable or disable writing to USB devices. Students are advised to create a 
(c) (i) This work is licensed under a Creative Commons Attribution 4.0 International License

system restore point before attempting this project.

Learning Goals: Modify the MS Windows Registry; Create a USB Write-Blocker

Software: MS Windows Regedit

1. In the MS Windows Start Search text box, type regedit and press Enter. This opens the Registry Editor from which you can access system folders and files.

2. In the editor, browse to and click to expand the $\backslash$ HKEY_LOCAL_MACHINE $\backslash$ SYSTE $\mathrm{M} \backslash$ CurrentControlSet key.

3. Right-click the Control subkey, click New.

4. The Registry Editor prompts the user for a key name. Enter USBDevicePolicy and press Enter. This creates a descendant key.

5. Right-click the USBDevicePolicy key, point to New, and click DWORD Value. If you have an option for 32-bit or 64-bit, click 32-bit.

6. In the prompt, type WriteProtect and press Enter.

7. In the key data area, right-click WriteProtect DWORD (or just WriteProtect) and click Modify.

8. In the Edit DWORD Value dialog box, change the Value Data setting from 0 to 1 , and then click $\mathbf{O K}$ to activate writeblocking to USB devices.

9. Right-click the USBDevicePolicy descendant key and click Export.

10. In the Export Registry File dialog box, click Desktop in the Save in list box. In the filename text box, type Write Protect USB ON, and click Save.
11. In the registry editor, click USBDevicePolicy. In the key data area, right-click WriteProtect DWORD and click Modify.

12. In the Edit DWORD Value dialog box, change the Value Data setting from 1 to 0 and click $\mathbf{O K}$ to deactivate write-blocking to USB devices.

13. Right-click USBDevicePolicy descendant key again and click Export.

14. In the Export Registry File dialog box, click Desktop in the Save in list box. In the File name text box, type Write Protect USB OFF, and click Save. Close the registry editor.

Forensic Project 5: Restoring an Image File to a Drive

Learning Goals: Restore an image file to a drive using the UNIX dd format for raw acquisition.

Software: ProDiscover Basic

Files: $\quad$ ForensicProject.eve

1. Transfer the data from the ForensicProject.eve file to the target drive (USB drive). Connect a USB drive to the workstation. Smaller USB drives work best as this exercise writes to the entire drive. I suggest 100-500 MB if available.

2. Start ProDiscover Basic and click Tools, Copy Disk.

3. In the dialog box click the Image to Disk tab.

4. From the work folder, click the ForensicProject.eve file and then click Open.

5. In the Copy source disk dialog box click in the area below Disk Name. 
(c) () This work is licensed under a Creative Commons Attribution 4.0 International License

6. Click the Disk Name list arrow

and then click the target drive, then click OK.

7. In the dialog box that opens click Write all 0's and then click OK. This begins the data loading and fills the remainder of the drive with 0's.

8. In the completion dialog box click OK to terminate loading.

Now you will use the raw acquisition format for creating an image file.

9. On your workstation click the Write Protect USB ON icon that you created earlier. This will protect the acquisition drive. Click Yes and then $\mathbf{O K}$ in the confirmation dialog boxes.

10. In ProDiscover Basic click Action, Capture Image from the menu.

11. In the dialog box, click the Source Drive list arrow and then click PhysicalDrive1.

12. Next to the Destination text box, click the $>>$ button and in the Save As dialog box navigate to the work folder and click Save.

13. In the Capture Image dialog box click the Image Format list arrow and click UNIX style dd format (for a raw acquisition). Click OK to start the acquisition and then click Proceed in the warning box. When the acquisition is complete click OK in the message box. The raw format creates the acquired file (.dd), a log file (.pds) and a hash file (.md5).

14. Click the Write Protect USB OFF button on the workstation desktop and remove the USB. Exit ProDiscover Basic. The suspect files are now imaged on the workstation in UNIX dd format.

\section{Forensic Project 6: Time and Date Information in MetaData}

Learning Goals: (a) How to locate time and date information from metadata, (b) How to identify file fragments found in the MFT records which could be found in unallocated disk space or the Pagefile.sys.

Software: ProDiscover Basic

1. Open Notepad and create a text file with the message: Not even computers will replace committees because committees buy computers. Save the file in the work folder as ForensicProj06A.txt. Exit Notepad.

2. Start ProDiscover Basic and begin a new project ForProj01A. Click Action and then Add.

3. In the Add Disk to Project dialog box click PhysicalDrive0. Type c-drive in the text box and click Add. If there is a warning message, click OK.

4. In the tree view, click to expand Content View, Disks, and PhysicalDrive0. Then click the $\mathbf{C}$ drive.

5. If necessary scroll down in the work area and right-click \$MFT and click Copy File. In the Save As dialog box, save the file to the work folder. Exit ProDiscover Basic.

6. Start the WinHex hex editor by clicking Start, All Programs, WinHex. If there is a warning message box, click OK.

7. On the toolbar click Open and navigate to the workfolder. Click the \$MFT file and then Open.

8. On the menu, click Search, Find Text.

9. In the text box for specifying a search string type ForensicProj06A.txt. Click the 
(c) () This work is licensed under a Creative Commons Attribution 4.0 International License

Format Code arrow, click Unicode and then click OK.

10. Right-click the Data Interpreter window and click Options. In the dialog box, click the Win32 FILETIME (64 bit) check box and then click $\mathbf{O K}$.

11. Scroll up so that the MFT record label FILE for ForensicProj06A.txt is the first line at the top of the hexadecimal and text displays.

12. Click at the beginning of the record, on the letter $\mathbf{F}$ in FILE, and then drag down and to the right while you watch the hex counter in the lower-right corner. When the counter reaches 50 release the mouse button.

13. Move the cursor to the next byte (one position to the left) and record the date and time of the Data Interpreter's FILETIME values.

14. Exit WinHex.

\section{Forensic Project 7: Conducting a Keyword Search}

Learning Goals: Conducting a keyword search

Software: AccessData FTK

1. Start AccessData FTK. Create a new case called ForProj07 for the case name and number. Click Next until the Add Evidence and Case dialog box appear.

2. Click Add Evidence, click Local Drive and then click Continue.

3. Insure that your USB drive (or local disk drive) and Logical Analysis are selected and then click $\mathbf{O K}$.

4. In the Evidence Information dialog box click to select your time zone and then click OK. Click Next and then click Finish. FTK will process the files and then indicate the evidence items.

5. Click Search, Tools, Analysis Tools from the menu, click to select the Full Text Indexing check box and then click OK.

6. In the search term text box type Diamond and then click Add. Click the View Cumulative Results button and then click OK in the Filter Search Hits dialog box. Repeat the search for the terms Gold, and Silver. The number of hits or occurrences of the search terms will appear under Search Items. (This will not include the items in the file slack space.)

7. Click Overview, Documents and then click. Scroll the upper-right pane until you see the word 'Diamond'. Note the logical sector position at the bottom of the upper-right pane.

8. Click the Search tab and then click Live Search. In the text box, type Diamond and make sure that ASCII and UNICODE are selected. Click Add and then the Search button, select All Files option and then click OK. When the search is complete click View Results to see the information displayed at the upper-right.

9. Click the expand $(+)$ buttons to find the search results. Scroll in the middle pane until you find 'Diamonds'.

10. Repeat steps 8 and 9 for 'Gold'.

11. The bottom pane displays details about the data FTK found including each occurrence of the word. Close FTK.

Forensic Project 8: Bit Rotation 
(c) () This work is licensed under a Creative Commons Attribution 4.0 International License.

One way of hiding information is to place the information in a file using a hex editor and corrupt the file so that it cannot be opened or, when opened, presents garbled data. This can be performed by simply rotating the bits in the file. To repair the file, simply rotate the bits back to their previous position.

Learning Goals: Bit shifting and rotation.

Software: AccessData FTK

Files: AccountNo2.txt
1. Start WinHex and open the file codes.txt.

2. Move the cursor over the toolbar buttons for Shift Left, Shift Right and note that Rotate Left, Rotate Right, Block Shift Left and Block Shift Right are also available. Click Rotate Right and create a screen print of the results for later comparison. Assume that the data is ordered in little endian. Then click $\mathbf{O K}$.

\begin{tabular}{|c|c|c|c|c|c|c|c|c|c|c|c|c|c|c|c|c|c|}
\hline \multirow{2}{*}{$\begin{array}{c}\text { AccountNo2.txt } \\
\text { Offset }\end{array}$} & & & & & & & & & & & & & & & & & \\
\hline & 0 & 1 & 2 & 3 & 4 & 5 & 6 & 7 & 8 & 9 & $\mathrm{~A}$ & B & $\mathrm{C}$ & D & $\mathrm{E}$ & $\mathrm{F}$ & \\
\hline 00000000 & 54 & 68 & 65 & 20 & 62 & 61 & $6 \mathrm{E}$ & $6 \mathrm{~B}$ & 20 & 61 & 63 & 63 & $6 \mathrm{~F}$ & 75 & $6 \mathrm{E}$ & 74 & The bank account \\
\hline 00000010 & 20 & $6 \mathrm{E}$ & 75 & $6 \mathrm{D}$ & 62 & 65 & 72 & 20 & 69 & 73 & 20 & 30 & 31 & 30 & 32 & 30 & number is 01020 \\
\hline 00000020 & 33 & 30 & 34 & 30 & 35 & 30 & 36 & $2 \mathrm{E}$ & OD & $0 \mathrm{~A}$ & 54 & 68 & 69 & 73 & 20 & 69 & 3040506. This i \\
\hline 000 & 73 & 20 & 68 & 69 & 67 & 68 & $6 \mathrm{C}$ & 79 & 20 & 63 & $6 \mathrm{~F}$ & $6 \mathrm{E}$ & 66 & 69 & 64 & 65 & s highly confide \\
\hline 000 & $6 \mathrm{E}$ & 74 & 69 & 61 & $6 \mathrm{C}$ & 20 & 73 & $6 \mathrm{~F}$ & 20 & $6 \mathrm{~B}$ & 65 & 65 & 70 & 20 & 69 & 74 & ntial so keep it \\
\hline 000 & 20 & 73 & 65 & 63 & 75 & 72 & 65 & $2 \mathrm{E}$ & 20 & 49 & 20 & 73 & 75 & 67 & 67 & 65 & secure. I sugge \\
\hline 000 & 73 & 74 & 20 & 70 & $6 \mathrm{C}$ & 61 & 63 & 69 & $6 \mathrm{E}$ & 67 & 20 & 69 & 74 & 20 & 69 & $6 \mathrm{E}$ & st placing it in \\
\hline 000 & 20 & 74 & 68 & 65 & 20 & 73 & 61 & 66 & 65 & $2 \mathrm{E}$ & 20 & OD & $0 \mathrm{~A}$ & 43 & $6 \mathrm{~F}$ & $6 \mathrm{D}$ & the safe. Com \\
\hline 000 & 70 & 61 & $6 E$ & 79 & 20 & 70 & $6 \mathrm{~F}$ & $6 \mathrm{C}$ & 69 & 63 & 79 & 20 & 72 & 65 & 73 & 74 & pany policy rest \\
\hline 000 & 72 & 69 & 63 & 74 & 73 & 20 & 74 & 68 & 65 & 20 & 75 & 73 & 65 & 20 & $6 \mathrm{~F}$ & 66 & ricts the use of \\
\hline 000 & 20 & 74 & 68 & 69 & 73 & 20 & 61 & 63 & 63 & $6 \mathrm{~F}$ & 75 & $6 \mathrm{E}$ & 74 & 20 & $6 \mathrm{E}$ & 75 & this account nu \\
\hline $000000 \mathrm{BO}$ & $6 \mathrm{D}$ & 62 & 65 & 72 & 20 & 74 & $6 \mathrm{~F}$ & 20 & 70 & 61 & 79 & 72 & $6 \mathrm{~F}$ & $6 \mathrm{C}$ & $6 \mathrm{C}$ & 20 & mber to payroll \\
\hline $000000 \mathrm{C0}$ & $6 \mathrm{~F}$ & $6 \mathrm{E}$ & $6 \mathrm{C}$ & 79 & $2 \mathrm{E}$ & OD & $0 \mathrm{~A}$ & 42 & 69 & 67 & 20 & 42 & $6 \mathrm{~F}$ & 73 & 73 & $2 \mathrm{C}$ & only. Big Boss, \\
\hline 00000000 & 20 & 43 & 45 & $4 \mathrm{~F}$ & OD & $0 \mathrm{~A}$ & & & & & & & & & & & \\
\hline
\end{tabular}

Figure 8. File Before Bit Shifting 
(a) (0) This work is licensed under a Creative Commons Attribution 4.0 International License.

\begin{tabular}{|c|c|c|c|c|c|c|c|c|c|c|c|c|c|c|c|c|c|}
\hline \multirow{2}{*}{$\begin{array}{c}\text { AccountNo2.txt } \\
\text { off set }\end{array}$} & \multirow[b]{2}{*}{0} & \multirow[b]{2}{*}{1} & \multirow[b]{2}{*}{2} & \multirow[b]{2}{*}{3} & \multirow[b]{2}{*}{4} & \multirow[b]{2}{*}{5} & \multirow[b]{2}{*}{6} & \multirow[b]{2}{*}{ 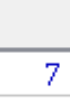 } & \multirow[b]{2}{*}{8} & \multirow[b]{2}{*}{9} & \multirow[b]{2}{*}{$A$} & \multirow[b]{2}{*}{$B$} & \multirow[b]{2}{*}{$\mathrm{C}$} & \multirow{3}{*}{\multicolumn{3}{|c|}{$\begin{array}{rrr}D & E & F \\
B A & B 7 & 3 A\end{array}$}} & \multirow[b]{3}{*}{ *42 $10 \cdot 5 \quad 0 \pm \pm \cdot 9 \cdot:$} \\
\hline & & & & & & & & & & & & & & & & & \\
\hline 00000000 & $2 \mathrm{~A}$ & 34 & 32 & 90 & 31 & 30 & B7 & 35 & 90 & 30 & $\mathrm{~B} 1$ & B1 & B7 & & & & \\
\hline 00000 & 10 & 37 & $3 \mathrm{~A}$ & $\mathrm{~B} 6$ & B1 & 32 & $\mathrm{Bg}$ & 10 & 34 & $\mathrm{Bg}$ & 90 & 18 & 18 & 98 & 19 & 18 & $7: 9 \pm 2^{1} \quad 4^{1} \quad$ I \\
\hline 000 & 19 & 98 & $1 \mathrm{~A}$ & 18 & $1 \mathrm{~A}$ & 98 & $1 \mathrm{~B}$ & 17 & 06 & 85 & $2 \mathrm{~A}$ & 34 & 34 & $\mathrm{~B} 9$ & 90 & 34 & I I I*441 4 \\
\hline 000 & $\mathrm{B9}$ & 90 & 34 & 34 & B3 & B4 & 36 & $3 \mathrm{C}$ & 90 & 31 & B7 & B7 & 33 & 34 & $\mathrm{~B} 2$ & 32 & $144^{3} 6<1 \cdots 34^{2} 2$ \\
\hline 000 & B7 & $3 A$ & 34 & BO & B6 & 10 & 39 & B7 & 90 & 35 & $\mathrm{~B} 2$ & $\mathrm{~B} 2$ & B8 & 10 & 34 & $\mathrm{BA}$ & $\cdot: 4^{\circ}$ 开 $9 \cdot 5^{22}, 49$ \\
\hline & 10 & 39 & $\mathrm{~B} 2$ & B 1 & $\mathrm{BA}$ & B9 & 32 & 97 & 10 & 24 & 90 & 39 & $\mathrm{BA}$ & B3 & B3 & B2 & $9^{2} \pm 0121 \leqslant 90332$ \\
\hline & $\mathrm{Bg}$ & $\mathrm{BA}$ & 10 & 38 & 36 & 30 & B1 & B4 & B7 & 33 & 90 & 34 & $\mathrm{BA}$ & 10 & 34 & B7 & $10860 \pm \cdot 3494$. \\
\hline & 10 & $3 A$ & 34 & 32 & 90 & 39 & $\mathrm{BO}$ & B3 & 32 & 97 & 10 & 06 & 85 & 21 & B7 & $\mathrm{B} 6$ & 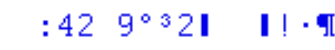 \\
\hline & $\mathrm{B} 8$ & 30 & B7 & $3 \mathrm{C}$ & 90 & 38 & 37 & B6 & 34 & B 1 & $\mathrm{BC}$ & 90 & 39 & 32 & B9 & $\mathrm{BA}$ & $0 \cdot<8794 \pm 1 / 492^{1} \mathrm{~g}$ \\
\hline & 39 & 34 & B1 & $\mathrm{BA}$ & 39 & 90 & $3 A$ & 34 & 32 & 90 & $3 \mathrm{~A}$ & $\mathrm{Bg}$ & $\mathrm{B} 2$ & 90 & 37 & B3 & $94 \pm 99: 42::^{12} 7^{3}$ \\
\hline 001 & 10 & $3 \mathrm{~A}$ & 34 & 34 & B9 & 90 & 30 & B 1 & B1 & B7 & $\mathrm{BA}$ & B7 & $3 A$ & 10 & 37 & $3 A$ & $: 44^{1} \quad 0 \pm \pm \cdot g \cdot: 7:$ \\
\hline 000 & B6 & B1 & 32 & B9 & 10 & $3 \mathrm{~A}$ & 37 & 90 & 38 & 30 & $\mathrm{BC}$ & B9 & 37 & $\mathrm{~B} 6$ & 36 & 10 & 9 $\pm 2^{1}: 7804^{1}{ }^{17}$ \\
\hline & 37 & B7 & 36 & $3 \mathrm{C}$ & 97 & 06 & 85 & 21 & 34 & B3 & 90 & 21 & 37 & $\mathrm{~B} 9$ & B9 & 96 & $7 \cdot 6<\mathbf{I}\left|4^{3} \quad\right| 7^{11} \mathbf{I}$ \\
\hline 000000D0 & 10 & & $\mathrm{~A} 2$ & A7 & 86 & 85 & & & & & & & & & & & ! c\$II \\
\hline
\end{tabular}

Figure 9. File After Bit Shifting

3. Click Rotate Left. In the Rotate Left Operation dialog box insure that the settings are the same as in the Treat Data As for Rotate Right. Otherwise, the bits will not be shifted equally. Save the file but do not close.

4. Click Shift Right and click OK $\underline{\text { twice }}$ and note what is happening with the data.

5. Click Block Shift Left. Attempt to reverse the procedure by clicking Block Shift Right, click Shift Left twice and click $\mathbf{O K}$ as needed.

6. Note that the data is garbled and the procedure has not been reversed. A shift (nonrotated) operation simply drops the bits as they are moved to the right or left and they cannot be recovered. Close the file but do not save. See Figures 8 and 9 .

\section{Forensic Project 9: Steganography}

Learning Goals: Hide a secret message using steganography.

Software: OpenPuff
Files: chihuly.jpg

1. Copy the chihuly.jpg file and rename chihuly_original.jpg

2. Start the OpenPuff software and click Hide (see Figure 10)

3. Uncheck boxes Enable [B] [C] and enter an 8 bit password in box $[\mathrm{A}]$ (see Figure 11)

4. In (2) browse to the Projects folder and select AccountNo2.txt (this contains your secret message)

5. In (3) click Add and browse to the chihuly.jpg file (this will be the carrier file)

6. In (3) click Hide Date (the contents of AccountNo2.txt is hidden in the chihuly.jpg file)

7. Save to another location as chihuly.jpg and then rename chihuly2.jpg.

8. Close OpenPuff and click Unhide and enter your password. In (3) open the chihuly2.jpg file. 


\section{(a) () This work is licensed under a Creative Commons Attribution 4.0 International License}

9. A text file containing the hidden message will appear on the desktop.

10. You may wish to open both the original and converted jpg images to see if you can discern a difference. They look exactly the same. One, however, contains a hidden message.

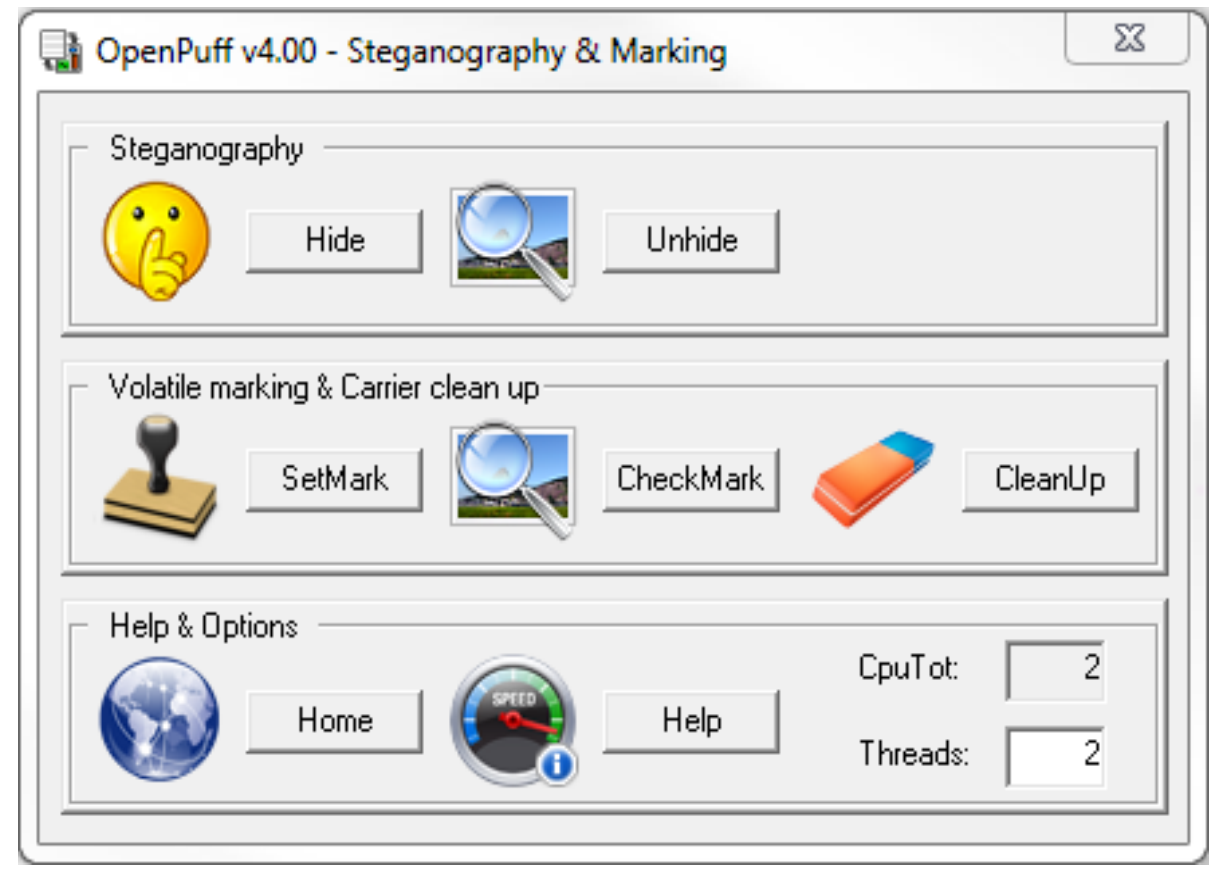

Figure 10. Chihuly.jpg file before Encoding 


\section{(9) 9 This work is licensed under a Creative Commons Attribution 4.0 International License}

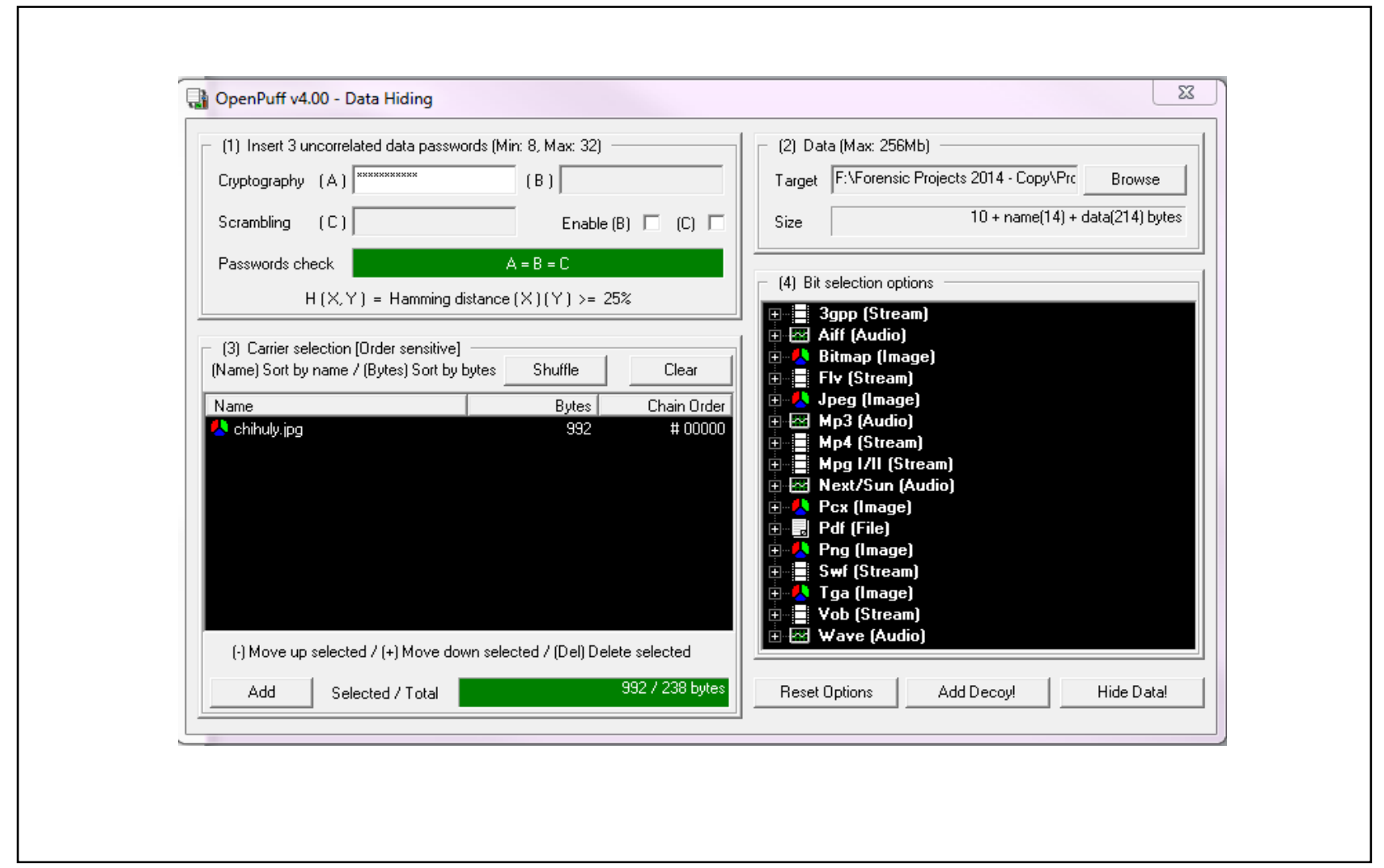

Figure 11. Adding Message to the File

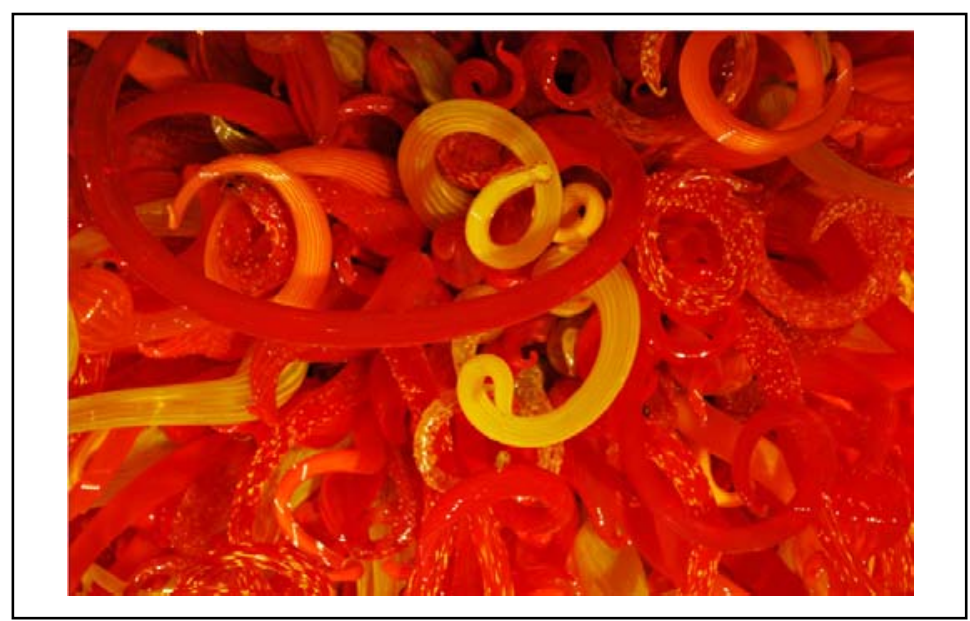

Figure 12. Chihuly.jpg File Containing Hidden Message

\section{DISCUSSION AND CONCLUSIONS}

This paper addresses the need for computer forensics education for accounting students.
While the forensic accounting profession continues to grow, most accounting students do not have exposure to a class in computer forensics. To be effective, it is essential that forensic accountants be knowledgeable of and 
(c) $(1)$ This work is licensed under a Creative Commons Attribution 4.0 International License

able to apply basic computer forensic skills. Forensic knowledge increases the ability to recognize and uncover fraud and helps meet the increased expectation for auditors in recognizing and uncovering fraud. These skills are important to accountants considering a career in auditing and especially IT auditing. They should also be useful in gaining entry-level positions with federal agencies such as the FBI, IRS and ATF that often use accountants to analyze computer files and digital devices.
The purpose of this paper is to present the educator with a number of exercises and projects that provide the accounting student with skills important to careers as forensic accountants and IT auditors. While students may not emerge from this course as experts in computer forensics they will develop a competence that is important to the organization. These skills can be extended in a variety of ways through pursuing advanced education in college courses, workshops and self-study tutorials. 
(c) $($ i) This work is licensed under a Creative Commons Attribution 4.0 International License REFERENCES

American Institute of Certified Professional Accountants (AICPA) (2013). AICPA top 10 tech. Retrieved from http://www.accountingtoday.com/gallery /AICPA2012-Top-10-Technology-

Initiatives-62024-1.html

AICPA Forensic and Valuation Services Section Task Force (2012) Computer Forensic Services and the CPA Practitioner, p. 6. Retrieved from http://www.aicpa.org/InterestAreas/Fore nsic

andValuation/Resources/PractAidsGuida nce/DownloadableDocuments/Computer \%20Forensic\%20Services\%20and\%20the\% 20CPA_Final.pdf

Busing, M.E., Null, J.D. \& Forcht, K.A. (2005/2006). Computer forensics: the modern crime fighting tool. The Journal of Computer Information Systems, 46(2), 115-119.

Casey, E. (2011). Digital Evidence and Computer Crime: Forensic Science, Computers, and the Internet, (3rd ed.). Maryland Heights, MO: Elsevier Science \& Technology/Syngress.

Coglitore, F.J. \& Matson, D.M. (2007). The use of computer-assisted auditing techniques in the auditing course: further evidence. Journal of Forensic Accounting, VIIII, 201-226.

Cory, S.N. \& Pruske, K.A. (2012). Necessary skills for accounting graduates: an exploratory study to determine what the profession wants. Proceedings of the American Society of Business and Behavioral Sciences Conference, Las Vegas, NV, 19(1), 208-218.
Davis, C., Schiller, M. \& Wheeler, K. (2007). IT Auditing. New York, NY: McGrawHill.

Hall, J. \& Singleton, T. (2005). Information Technology and Assurance, (2nd ed.). Thomson South-Western, Mason, OH.

Hurt, B. (2007). Teaching what matters: a new conception of accounting education. Journal of Education for Business, 82(5), 295-299.

Kearns, G. (2010). Computer forensics for graduate accountants: a motivational curriculum approach. Journal of Digital Forensics, Security and Law, 5(2), 63-83.

Merhout, J. W. \& Buchman, S. E. (2007). Requisite skills and knowledge for entrylevel IT auditors. Journal of Information Systems Education, 18(4), 469-477.

Nelson, B., Phillips, A., \& Steuart, C. (2010). Guide to Computer Forensics and Investigations, (4th ed.). Boston, MA: Cengage/Course Technology.

O'Donnell, J. \& Moore, J. (2005). Are accounting programs providing fundamental IT control knowledge? The CPA Journal, 75(5), 64-66.

Pearson, T. A. \& Singleton, T. W. (2008). Fraud and forensic accounting in the digital environment. Issues in Accounting Education, 23(4), 545-559.

Sammons, J. (2012). The Basics of Digital Forensics: The Primer for Getting Started in Digital Forensics. Maryland Heights, MO: Elsevier Science \& Technology/Syngress.

SAS 99 (Statement on Audit Standards 99: Consideration of Fraud in a Financial Statement Audit) (2002). Retrieved from 
(c) $\left(\begin{array}{c}\text { ir } \\ \text { ir }\end{array}\right.$ http://www.aicpa.org/Research/Standar ds/AuditAttest/DownloadableDocuments /AU-00316.pdf

Seda, M., Kramer, B. \& Peterson, K. (2008). The emergence of forensic accounting programs in higher education. Management Accounting Quarterly, 9(3), 15-23.

Tsu, T. (January, 2014). Target traces data breach to credentials stolen from vendor. Los Angeles Times. Retrieved from http://www.latimes.com/business/money /la-fi-mo-target-data-breach-vendor20140129,0,8026.story\#axzz2rzEFEbhQ

Walters, R. (2014). Cyber attacks on U.S. companies in 2014. The Heritage Foundation. Retrieved from http://www.heritage.org/research/report s/2014/10/cyber-attacks-on-uscompanies-in-2014 